\title{
IMPACTOS ECONÔMICOS, SOCIAIS E AMBIENTAIS DO PRONAF NO BRASIL: UMA REVISÃO SISTEMÁTICA DA LITERATURA
}

\author{
Carina Chagas Madeira de Souza ${ }^{1}$ \\ Fabrício Khoury Rebello ${ }^{2}$ \\ Marcos Antônio Souza dos Santos ${ }^{3}$
}

Resumo: $O$ estudo analisa o quantitativo de publicações científicas relacionadas aos impactos do Programa Nacional de Fortalecimento da Agricultura Familiar (PRONAF) na agricultura familiar no Brasil, de modo a identificar quais são as principais abordagens dentro desta temática e apontar eventuais lacunas de pesquisa. Para tal finalidade, foi realizada uma revisão sistemática da literatura no período de 2000 a 2020. A pesquisa catalogou 58 artigos e entre os principais resultados destacam-se o nível de abrangência do PRONAF, melhorias no setor produtivo e promoção do desenvolvimento regional. Já os maiores desafios encontram-se na elevada concentração dos recursos, processos burocráticos, participação pouco efetiva de grupos marginalizados, baixa qualidade da assistência técnica, comoditização da produção e a pouca ênfase dada às questões ambientais.

Palavras-chave: Agricultura familiar. Financiamentos agropecuários. Política de crédito.

\section{ECONOMIC, SOCIAL AND ENVIRONMENTAL IMPACTS OF PRONAF IN BRAZIL: A SYSTEMATIC LITERATURE REVIEW}

Abstract: The study analyzes the quantity of scientific publications related to impacts of Programa Nacional de Fortalecimento da Agricultura Familiar (PRONAF) on family farming in Brazil, in order to identify the main approaches within this theme and point eventual lack of research. For this purpose, it was used a systematic literature review from 2000 to 2020. The research cataloged 58 articles and among the main results we highlight the level of coverage of PRONAF, improvements in the productive sector and promotion of regional development. The biggest challenges are found in the high concentration of resource, bureaucratic processes, ineffective participation of marginalized groups, low quantity of technical assistance, commoditization of production and low emphasis on environmental issues.

Key-words: Family farming. Agricultural financing. Credit policy.

\section{IMPACTOS ECONÓMICOS, SOCIALES Y AMBIENTALES DEL PRONAF EN BRASIL: UNA REVISIÓN SISTEMÁTICA DE LA LITERATURA}

Resumen: El estudio busca un análisis del quantitativo de las publicaciones científicas relacionadas a los impactos del Programa Nacional de Fortalecimento da Agricultura Familiar (PRONAF) en la agricultura familiar en el Brasil, así como a identificar cuáles son las principales abordajes de esta temática y apuntar eventuales lacunas de búsquedas. Para eso, fue realizada una revisión sistemática de la literatura de los años de 2000 hasta 2020. La búsqueda catalogó 58 articulos y

\footnotetext{
${ }^{1}$ Universidade Federal Rural da Amazônia (UFRA), Mestra pelo Programa de Pós-Graduação em Agronomia (PGAGRO), Belém-PA, Brasil, carinamadeira95@gmail.com, https://orcid.org/0000-00030630-8025.

${ }^{2}$ Universidade Federal Rural da Amazônia (UFRA), Professor do Programa de Pós-Graduação em Agronomia, Belém-PA, Brasil, fabriciorebello@hotmail.com, https://orcid.org/0000-0003-2398-4906.

${ }^{3}$ Universidade Federal Rural da Amazônia (UFRA), Professor do Programa de Pós-Graduação em Agronomia, Belém-PA, Brasil, marcos.marituba@gmail.com, https://orcid.org/0000-0003-1028-1515.
} 
entre los principales resultados se destaca el nivel de cobertura del PRONAF, mejorías en el sector productivo y promoción del desarrollo regional. Los desafíos más grandes se encuentran en la elevada concentración de los recursos, procesos burocráticos, participación poco efectiva de los grupos marginados, baja calidad de la asistencia técnica, comoditización de la producción y poca énfasis a las cuestiones ambientales.

Palabras-clave: Agricultura familiar. Financiamiento agropecuario. Políticas de crédito.

\section{Introdução}

A produção familiar exerce papel importante na economia, principalmente pela oferta de produtos básicos que abastecem a mesa dos brasileiros como o café, banana, mandioca, abacaxi e feijão. Segundo o Censo Agropecuário de 2017 (IBGE, 2020), o número total destes estabelecimentos é de 3,8 milhões, o que representa $76,8 \%$ de todas as unidades agropecuárias do Brasil. Entretanto, apesar de sua inegável importância, essa classe de trabalhadores convive com uma série de desvantagens históricas, dado que até o final do século $X X$ inexistiam políticas públicas específicas para o apoio de suas atividades e a modernização agrícola do país foi marcada pela notória participação de bancos oficias responsáveis por financiar atividades características da agricultura patronal (GRISA; SCHNEIDER, 2014; ARAÚJO; VIEIRA FILHO, 2018).

Foi, então, a partir do início da década de 1990 que esta situação começou a mudar. Neste período, várias reivindicações de pequenos trabalhadores rurais buscando inovações e políticas públicas específicas para a classe disseminaram-se por todo o país, dando origem ao movimento conhecido nacionalmente como "Gritos da terra Brasil”, em 1994 (MATTEI, 2005). As exigências apresentadas pelos Gritos resultaram na criação do Programa Nacional de Fortalecimento da Agricultura Familiar (PRONAF) em 1995, com o intuito de fortalecer o exercício dos agricultores familiares através do financiamento de projetos que estimulam a renda, produção e emprego da mão de obra (ARAUJO; VIEIRA FILHO, 2018).

Desde a implantação do Programa, muitos trabalhos foram desenvolvidos revelando a notória atenção acadêmica para captar as principais contribuições desta política no desenvolvimento rural. Neste sentido, a presente revisão foi desenvolvida com o intuito de analisar o aparato geral das publicações que tratam da repercussão do PRONAF sobre a pequena produção familiar.

Para o cumprimento deste objetivo, a partir do uso de descritores, procedeuse a busca e seleção de artigos publicados em periódicos indexados nas bases da 
Scopus, Scielo, Web Of Science, Periódicos Capes e, adicionalmente, nas revistas Econômica do Nordeste e Amazônia: Ciência \& Desenvolvimento, com o intuito de identificar qual o cenário das pesquisas científicas relacionadas aos impactos econômicos, sociais e ambientais da política de financiamento para os agricultores familiares (PRONAF) nos últimos vinte anos (2000 a 2020).

A importância prática deste tipo de levantamento consiste na identificação das principais lacunas analíticas neste tema, tendo em vista que os resultados fornecem subsídios necessários para orientar novas pesquisas de monitoramento e aperfeiçoamento desta política.

\section{O PRONAF na literatura especializada:}

Aspectos históricos do crédito rural no Brasil e as primeiras manifestações a favor da produção familiar

A institucionalização do crédito rural no Brasil foi caracterizada pela criação do Sistema Nacional de Crédito Rural (SNCR) em 1965, cujo sistema de financiamento contou com o apoio de toda a rede bancária. O país, que até então adotara um modelo de industrialização no setor agropecuário, passou por momentos de crises que agravaram o abastecimento alimentar interno e provocou aumento das taxas de inflação. Estas dificuldades conduziram um processo de modernização agrícola nacional altamente seletivo, beneficiando principalmente os médios e grandes agricultores das Regiões Sul com diversas ações e políticas públicas como a criação do SNCR, políticas de garantia de preços mínimos e investimentos em pesquisa e extensão rural (GRISA; SCHNEIDER, 2014).

No início dos anos de 1970, os efeitos da crise internacional do petróleo ocasionaram pressão inflacionária na economia brasileira, forçando uma reavaliação das prioridades na política agrícola, que passou, então, a aumentar o volume de recursos, subsídios e a participação de autoridades monetárias no sistema financeiro a fim de contornar os desequilíbrios econômicos ocasionados pelas crises vivenciadas dentro e fora do país. Esta maneira de conduzir a política de crédito rural acabou exaurindo suas potencialidades em razão da baixa de recursos. Mediante essas dificuldades, a política de crédito rural passou a ser duramente criticada em termos de equidade, eficiência e impactos sobre a política monetária (BARROS, 1979; SPOLADOR, 2001).

Assim, diante de todas as barreiras enfrentadas no final da década de 1970 e início dos anos 1980, a Política Nacional de Crédito Rural passou por um 
realinhamento de suas estratégias. A nova fase buscou reduzir gradualmente a participação direta do governo nas concessões e aumentar a participação da iniciativa privada no custeio e comercialização do agronegócio, ambos com o intuito de controlar os gastos do setor público (CASTRO, 2017). Ao longo desse processo, o grupo de pequenos agricultores excluídos da modernização e crescimento econômico do país, viam agravar sua situação perante o cenário de crise, pois o crédito ficara ainda mais seletivo (BIANCHINI, 2015).

Na tentativa de incentivar novas fontes não-inflacionárias de financiamento, foram criados em 1988 os Fundos Constitucionais de Financiamento do Norte (FNO), Nordeste (FNE) e Centro-Oeste (FCO), aos quais operavam com 3\% das receitas da União. Este valor era distribuído entre as regiões $(0,6 \% \mathrm{FNO}, 0,6 \% \mathrm{FCO}$ e 1,8\% FNE) para dar capilaridade aos recursos e beneficiar os territórios menos favorecidas do país (RAMOS; MARTHA JUNIOR, 2010), constituindo-se na primeira fonte estável de recurso para o desenvolvimento regional a partir do crédito direcionado ao setor produtivo (ARAÚJO et al., 2015).

Sobre a atuação dos Fundos, Tura e Costa (2000, p. 30) ressaltam que este foi um mecanismo alternativo criado para atender públicos específicos, compostos por mini e pequenos produtores e empresários, cujas preferências de financiamento envolviam atividades com uso de mão de obra e matérias-primas locais e a produção de alimentos básicos para suprir demandas internas.

Considerando essa iniciativa e o contexto histórico vivenciado no país (críticas ao modelo desenvolvimentista, abertura política e reorganização de movimentos sindicais de trabalhadores), nesse período surgiram várias mobilizações para potencializar o caráter dos Fundos como uma ferramenta em harmonia com os interesses da classe. No caso da Amazônia, nos anos de 1990, este movimento ficou conhecido como a "Luta pela democratização e desburocratização do acesso de pequenos produtores rurais ao FNO", que mais tarde, em 1993, passou a se chamar "Gritos dos Povos da Amazônia por Cidadania e Desenvolvimento" (TURA; COSTA, 2000).

Neste mesmo período, a economia brasileira fortemente afetada pela maior abertura aos mercados internacionais e desregulamentação dos mercados, submeteu o país a uma intensa concorrência com os países do Mercosul. Os produtores, fragilizados diante da nova conjuntura de mercado e ainda sofrendo os efeitos da crise de 1980, contraíram dívidas que marcaram o início da década de 1990 com grande inadimplência no setor (SCHNEIDER; MATTEI; CAZELLA, 2004). 
A partir daí, houve, então, maior articulação entre as organizações de pequenos agricultores e a Confederação Nacional dos Trabalhadores na Agricultura (CONTAG) e ao Departamento Nacional de Trabalhadores Rurais (DNTR). Este último, se manteve bastante focado nas lutas em favor da "reconversão e reestruturação produtiva" dos produtores familiares, pois os mesmos seriam muito prejudicados pelo processo de abertura econômica. Assim, as reivindicações favoráveis à agricultura familiar, que começaram a ter voz ainda em 1988 com os Fundos, ganharam forças na primeira metade da década de 1990, por meio do "Grito da Terra Brasil" (SCHNEIDER; MATTEI; CAZELLA, 2004).

\section{A criação do Programa Nacional de Fortalecimento da Agricultura Familiar (PRONAF) e sua evolução como política pública}

Em resposta às reivindicações para a criação de políticas específicas aos pequenos trabalhadores rurais, foi criado em 1994 o Programa de Valorização da Pequena Produção Rural (PROVAP), que passou por reformulações e deu origem ao Programa Nacional de Fortalecimento da Agricultura Familiar (PRONAF) em 1995, cuja institucionalização ocorreu através do Decreto no 1.946, de 28/07/1996 (MATTEI, 2005).

Pensada como uma política pública dedicada ao fortalecimento da agricultura familiar, o PRONAF, mediante a oferta de suporte técnico e financeiro, tem o propósito de contribuir para desenvolvimento rural sustentável através do fortalecimento da capacidade produtiva, geração de emprego e renda no meio rural (SCHNEIDER; MATTEI; CAZELLA, 2004).

No que compete ao financiamento da produção, este apoio está relacionado a oferta de recursos para agricultores familiares enquadrados em diferentes categorias de beneficiários ( $A, A / C$ e $B$ ). Essa categorização por grupos especiais viabilizou a criação de regras financeiras mais adequadas às especificidades de cada segmento social (GRZYBOWSKI et al., 2006; BIANCHINI, 2015). O grupo B, por exemplo, é composto por agricultores familiares de baixo potencial produtivo cuja renda bruta anual é de até $R \$ 23.000,00$. Já os grupos $A$ e $A / C$ incluem assentados da reforma agrária que desejam requerer crédito para investimento ou comercialização (BNB, 2020).

Muitas mudanças institucionais, sobretudo a partir de 1999, contribuíram para a consolidação do Programa. Primeiramente, o PRONAF deixou de fazer parte do Ministério da Agricultura, Pecuária e Abastecimento (MAPA) para compor o 
Ministério do Desenvolvimento Agrário (MDA) juntamente com a política fundiária do Instituto de Colonização e Reforma Agrária (INCRA). Além disso, foi criada a Secretaria de Agricultura Familiar (SAF), responsável por atender ações de interesse específico deste público (GRZYBOWSKI et al., 2006) e; no ano de 2003 foi criado o Plano Safra da Agricultura Familiar, iniciativa que vinha aumentando a capilaridade do MDA e seus parceiros, através do aperfeiçoamento e implementação de novas políticas agrícolas (BRASIL, 2015).

Todo esse conjunto de alterações ocasionou também o surgimento de várias linhas de crédito para atividades especiais, como o PRONAF Agroecologia, Eco, Floresta, Agroindústria, Mais Alimentos, Turismo Rural, entre outros, além de incluir Mulheres, Jovens e Pescadores (SILVA, 2012).

Com mais de vinte e cinco anos de existência, o PRONAF vem se destacando na oferta de microcrédito para a produção familiar. Em termos quantitativos, soma $\mathrm{R} \$ 389,3$ bilhões de recursos aplicados entre 1999 e 2019. A dotação do Programa para 2020 (janeiro a agosto) é da ordem de $R \$ 132,3$ bilhões, conforme a correção de preços realizada através do Índice Geral de Preços Disponibilidade Interna (IGP- DI), ano-base 2019, do Instituto de Economia Aplicada (IPEA, 2020).

Durante todo o período analisado, houve um aumento dos recursos disponibilizados e do número de beneficiários. Em termos percentuais, este aumento representou acréscimos de $71,53 \%$ nas contratações e $226,78 \%$ no total investido.

Contudo, a distribuição dos financiamentos do PRONAF-Crédito no Brasil, entre 1999 e 2019, tem sido bastante desigual entre as regiões. O montante captado pelas Regiões Sul e Sudeste corresponderam a $R \$ 198$ bilhões $(50,86 \%)$ e $R \$ 76$ bilhões (19,53\%), respectivamente. Já o Nordeste, Centro-Oeste e Norte acumularam, nesta mesma ordem, $R \$ 57$ bilhões (14,90\%), $R \$ 27$ bilhões $(6,96 \%)$ e $\mathrm{R} \$ 25$ bilhões (6,56\%).

Ao se considerar o valor médio das operações neste mesmo período, as regiões com contratos médios mais elevados, são Centro-Oeste ( $R \$ 27.181,78)$, Sul $(R \$ 19.022,70)$, Norte $(R \$ 18.921,92)$ e Sudeste $(R \$ 16.662,78)$, que contrastam com a Região Nordeste $(\mathrm{R} \$ 4.489,56)$ em termos de valor médio por contrato (BCB, 2020).

O entendimento destes números diz muito a respeito da dinâmica de distribuição dos financiamentos do PRONAF. Pelo que se percebe, a maioria dos recursos aplicados se destinam às Regiões Sul e Sudeste, que juntamente com o 
Centro-Oeste, reúnem os beneficiários mais capitalizados do PRONAF, conforme também apontado por Grisa, Wesz Junior e Buchweitz (2014).

\section{Metodologia}

Conforme a classificação proposta por Silva e Menezes (2001), esta é uma pesquisa de natureza aplicada, pois seu desenvolvimento objetiva a geração de conhecimentos para aplicação prática e resolução de problemas específicos; exploratória e descritiva do ponto de vista de seus objetivos; possui uma abordagem qualitativa, pois os pesquisadores tendem a analisar os dados de forma holística e interpretativa; e na perspectiva dos procedimentos técnicos, enquadra-se em uma revisão sistemática de literatura.

Isto posto, as etapas para a construção deste estudo foram as seguintes: i) formular a pergunta de pesquisa; ii) identificar as bases de dados e definir as estratégias de busca; iii) selecionar e acessar a literatura; iv) avaliar a qualidade da literatura incluída na avaliação; e, v) analisar, sintetizar e divulgar os resultados (CRONIN; RYAN; COUGHLAN, 2008).

O cumprimento desse protocolo, neste trabalho, é explicitado a seguir:

I. Pergunta de pesquisa: qual o cenário das pesquisas científicas relacionadas aos impactos diretos da política de financiamento para os agricultores familiares (PRONAF) no período de 2000 a $2020 ?$

II. Bases de dados pesquisadas e as estratégias de busca: foram predefinidas quatro bases de dados científicas, sendo estas: Scopus, Scielo, Web of Science e Periódicos Capes. Adicionalmente, foram realizadas buscas diretas na Revista Econômica do Nordeste (REN) e Revista Amazônia: Ciência \& Desenvolvimento, conceituados periódicos científicos especializados em temas relacionados às economias das Regiões Nordeste e Norte do Brasil, editados, respectivamente, pelo Banco do Nordeste (BNB) e Banco da Amazônia (BASA), bancos de desenvolvimento regionais oficiais e operadores dos recursos dos Fundos Constitucionais e PRONAF nas duas regiões, e, presumivelmente, fonte de interesse dos pesquisadores para divulgação de suas pesquisas sobre crédito rural. Os textos analisados pertencem a diferentes áreas do conhecimento, visto o caráter multidisciplinar desta política.

Após a seleção dos bancos de dados, foi definido o período das publicações. O recorte temporal compreendeu aos anos de 2000 a 2020, em todos os seus meses de cobertura (janeiro a dezembro), com exceção para o ano de 2020 , 
pois este levantamento foi realizado entre os meses de março a maio deste mesmo ano. Em seguida, foram determinados os descritores a serem utilizados, que foram: Impact* AND PRONAF; Agricult* AND PRONAF; "Family farming" AND PRONAF; PRONAF AND (desenvolvimento OR modernização); PRONAF AND (develop* OR moder ${ }^{\star}$ ); PRONAF AND (inadimplência OR default); PRONAF AND (sustentabilidade OR sustainability OR environmental). Salienta-se que nas bases Scopus, Scielo e Web of Science as buscas são permitidas somente no título, resumo e palavraschave, sendo, portando, utilizado esse filtro. Diferentemente do Portal de Periódicos Capes, onde a pesquisa foi realizada em todos os termos dos artigos e por isso apresentou números elevados de trabalhos retornados. Quanto à busca direta nos periódicos, os descritores foram utilizados apenas na revista REN, uma vez que a revista Amazônia: Ciência \& Desenvolvimento não abriga seus estudos em uma plataforma sistematizada, forçando, então, a busca direta dos artigos no próprio sumário de cada edição.

III. Critérios de inclusão e exclusão: para seleção dos artigos enquadrados na pergunta de pesquisa foi realizada a leitura do título, resumo, palavras-chave e conclusões de todos os artigos retornados em cada base, escolhendo aqueles que de alguma forma abordavam os impactos socioeconômicos e ambientais do PRONAF. A pesquisa respeitou a seguinte ordem: Scopus, Scielo, Web of Science, Portal de Periódicos Capes, REN e Revista Amazônia: Ciência \& Desenvolvimento, sendo desconsiderados artigos repetidos em mais de uma base.

IV. Análise crítica dos estudos selecionados: procedeu-se a leitura integral dos artigos escolhidos na etapa anterior, visando extrair aspectos relevantes dos objetivos, metodologia, resultados e conclusões de cada estudo.

V. Síntese dos resultados: a exposição dos resultados teve como enfoque a descrição das principais características dos estudos, tais como os locais de realização, metodologias e abordagens que tem sido amplamente utilizada.

\section{Resultados e discussões}

O levantamento geral retornou um total de 1.765 artigos científicos dos quais foram catalogados 58 (Tabela 1). De modo geral, as abordagens das pesquisas estiveram muito alinhadas com a percepção dos efeitos desta política nas esferas sociais, produtivas e de desenvolvimento regional, sinalizando uma crescente atenção acadêmica em analisar o desempenho setorial dessa política pública. 
Tabela 1 - Número de artigos retornados e selecionados para cada descritor e bases científicas no período de 2000 a 2020.

\begin{tabular}{ccccccccc}
\hline Descritor & & Scopus & Scielo & $\begin{array}{c}\text { Web of } \\
\text { Science }\end{array}$ & $\begin{array}{c}\text { Periódicos } \\
\text { Capes }\end{array}$ & REN & $\begin{array}{c}\text { Amazônia: } \\
\text { C\&D* }^{*}\end{array}$ \\
\hline Impact* and & Retornados & 9 & 6 & 13 & 248 & 2 & - \\
PRONAF & Selecionados & 4 & 2 & 0 & 8 & 1 & - \\
\hline Agricult* AND & Retornados & 40 & 35 & 20 & 373 & 24 & - \\
PRONAF & Selecionados & 10 & 5 & 4 & 11 & 6 & - \\
\hline "Family farming" & Retornados & 2 & 18 & 14 & 93 & 0 & - \\
AND PRONAF & Selecionados & 2 & 0 & 1 & 0 & 0 & - \\
\hline $\begin{array}{c}\text { PRONAF AND } \\
\text { (desenvolvimento }\end{array}$ & Retornados & 5 & 16 & 0 & 250 & 19 & - \\
OR modernização) & Selecionados & 1 & 0 & 0 & 0 & 0 & - \\
\hline $\begin{array}{c}\text { PRONAF AND } \\
\text { (develop* OR } \\
\text { modern*) }\end{array}$ & Retornados & 22 & 0 & 16 & 268 & 5 & - \\
\hline PRONAF AND & Selecionados & 0 & 0 & 0 & 0 & 0 & - \\
(Inadimplência OR & Retornados & 2 & 0 & 1 & 47 & 0 & - \\
Default) & Selecionados & 0 & 0 & 0 & 0 & 0 & - \\
\hline $\begin{array}{c}\text { PRONAF AND } \\
\text { (Sustentabilidade }\end{array}$ & Retornados & 5 & 0 & 2 & 208 & 2 & - \\
OR Sustainability & Selecionados & 1 & 0 & 0 & 0 & 0 & - \\
OR Environmental) & & Retornados & $\mathbf{8 5}$ & $\mathbf{7 5}$ & $\mathbf{6 6}$ & $\mathbf{1 . 4 8 7}$ & $\mathbf{5 2}$ & - \\
\hline Total & Selecionados & $\mathbf{1 8}$ & $\mathbf{7}$ & $\mathbf{5}$ & $\mathbf{1 9}$ & $\mathbf{7}$ & $\mathbf{2}$ \\
\hline
\end{tabular}

Nota: *Busca realizada diretamente no sumário de todas as edições

Fonte: dados da pesquisa.

No que se refere à distribuição temporal das publicações, inicialmente, no período de 2000 a 2005 os registros catalogaram apenas uma publicação, já que neste momento o Programa era recém criado. Mesmo diante disto, essa única avaliação apresentou reflexões contundentes sobre o impacto do Programa no Rio Grande do Sul.

Entre 2006 e 2010, os estudos foram mais diversos e contaram com temas relacionados à experiência de crédito pelos beneficiários; análises de linhas específicas; e, avaliações de impacto nas dimensões econômicas e produtivas. Ao todo, neste período foram somadas 11 investigações. Já os 22 artigos publicados entre 2011 e 2015 fizeram apontamentos semelhantes, incluindo, ainda, vários levantamentos retratando a evolução dos financiamentos do PRONAF ao longo dos anos. Por fim, entre os anos de 2016 e 2019 foram identificadas 24 pesquisas que mantiveram as abordagens já citadas anteriormente, contando com a maior presença de diagnósticos locais em nível de impacto.

Essa prospecção do número de estudos esteve muito relacionada ao comportamento do Programa ao longo dos anos, tendo em vista que a maior abrangência do PRONAF em nível nacional abriu espaço para maiores discussões sobre os seus efeitos na escala local e regional ao mesmo tempo em que a abertura 
de novas linhas e grupos específicos conduziu maiores estudos (MATTEI, 2006; MARIONI et al., 2016).

O pico de produção acadêmica ocorreu em 2014, Ano Internacional da Agricultura Familiar declarada pela Organização das Nações Unidas (ONU), pelo qual possivelmente estimulou a divulgação de maiores estudos nesta linha. Apesar de não terem sido encontrados registros para o ano de 2020, o que se justifica pelos poucos meses de cobertura no momento da realização deste levantamento (março a maio de 2020), ressalta-se que a tendência para maiores investigações nos próximos anos é positiva, pois de acordo com Mattei (2006) e Marioni et al. (2016), o PRONAF é uma estratégia que carece de avaliação contínua para garantir o cumprimento de seus objetivos. Portanto, o aumento gradual no número de estudos é algo esperado.

Periódicos das mais diversas áreas abrigam pesquisas envolvendo 0 PRONAF. Nesta revisão, os periódicos que somaram para estas discussões pertenciam ao ramo da Economia, Sociologia Rural, Desenvolvimento Regional, Geografia, Administração e Ciências Agrárias. Na Tabela 2 é exibido o rol das revistas filtradas nesta pesquisa.

Percebe-se que a Revista de Economia e Sociologia Rural reúne a maior parte dos estudos selecionados (14), sendo, portanto, caracterizada como uma revista que atrai bastante interesse dos autores, provavelmente em razão de seu bom ranking no Qualis geral da CAPES para o quadriênio de 2013 a 2016, onde se encontra classificada como A2 (Planejamento Urbano e Regional) e B1 (Ciências Agrárias I, Economia e Interdisciplinar). Outra motivação que pode estar levando a maior procura deste periódico seria a sua tradição, há mais de 30 anos, em abordar tópicos relacionados à agricultura no meio científico ("Rev. Econ. e Sociol. Rural”, 2020).

Tabela 2 - Relação dos periódicos mais visados para publicações sobre o PRONAF, 2000 a 2019.

\begin{tabular}{lc}
\hline Periódico & Artigos \\
\hline Revista de Economia e Sociologia Rural (RESR) & 14 \\
Revista Econômica do Nordeste (REN) & 7 \\
Desenvolvimento e Meio Ambiente & 3 \\
Boletim Goiano de Geografia (BGG) & 2 \\
Economia \& Região & 2 \\
GEO UERJ & 2 \\
Revista do Desenvolvimento Regional (REDES) & 2 \\
Revista Brasileira de Gestão e Desenvolvimento Regional (G\&DR) & 2 \\
Revista Verde de Agroecologia e Desenvolvimento Sustentável & 2 \\
Sociedade \& Natureza & 2
\end{tabular}


Amazônia: Ciência e Desenvolvimento 2

Desenvolvimento em Questão 1

Economia Aplicada 1

Espacios 1

Estudos Sociedade e Agricultura (ESA)

Geosul 1

Polis - Revista Latinoamericana 1

RA' E GA - O espaço geográfico em análise $\quad 1$

Review of Development Economics 1

Revista ENIAC Pesquisa 1

Revista Brasileira de Agropecuária Sustentável (RBAS) 1

Revista Brasileira de Economia (RBE) 1

Revista Brasileira de Planejamento e Desenvolvimento (RBPD) 1

Revista Expressão Católica 1

Revista Geográfica Acadêmica (RGA) 1

Revista Gesto - Revista de Gestão Estratégica de Organizações 1

Revista Principia: divulgação científica e tecnológica do IFPB 1

Revista Tamoios 1

Tropical and Subtropical Agroecosystems 1

Total $\quad 58$

Fonte: dados da pesquisa.

Outro periódico com boa participação na quantidade de artigos foi a Revista Econômica do Nordeste (REN), um periódico muito prestigiado em pesquisas com foco no desenvolvimento da região. Ao todo, a revista retornou sete artigos filtrados nessa revisão. Entretanto, embora seja um periódico importante na temática do PRONAF, as pesquisas oriundas desta revista apresentam maior foco na Região Nordeste.

Além disso, ainda que o PRONAF seja uma política genuinamente brasileira, quatro periódicos internacionais abrigaram pesquisas relevantes sobre os efeitos desta política para a sistematização da agricultura familiar no Brasil, contribuindo para este debate em nível internacional. Foram estes: Espacios (1); Polis (1); Review of Development Economics (1); e Tropical and Subtropical Agroecosystems (1), conforme consta na Tabela 2.

Considerando a dimensão espacial dos artigos científicos, os resultados demonstraram uma maioria de trabalhos desenvolvidos em nível nacional $(32,8 \%)$, seguido pelas Regiões Sul (25,9\%), Sudeste (17,2\%), Nordeste (13,8\%), Norte $(5,2 \%)$, Centro-Oeste (3,4\%); e, Amazônia Legal (1,7\%), que é composta por todos os estados da Região Norte mais o Mato Grosso e parte do Maranhão.

Com base nestas análises, nota-se que a realização de pesquisas segue a lógica de participação das regiões brasileiras na alocação dos recursos do PRONAF, pois novamente as Regiões Sul e Sudeste recebem maior atenção. A respeito disso, 
Marioni et al. (2016) destaca que a construção histórica do programa juntamente com a consolidada estrutura organizacional dos agricultores familiares nestes locais, são fatores que colaboram para a maior atuação do Programa. Outra explicação para isto é o maior número de pesquisadores desenvolvendo trabalhos nestes locais, haja vista que $63,14 \%$ dos pesquisadores brasileiros exercem suas atividades de pesquisa no Sul e Sudeste (CNPQ, 2020).

O baixo número de pesquisas realizadas nos demais territórios é algo que merece atenção, dado que a lógica do Programa possui fundamental importância em locais onde a agricultura familiar permanece fragilizada. Além disso, considerando que a região Amazônica oferece um conjunto de serviços ambientais indispensáveis para a sociedade, a academia deveria dar maior destaque para a compreensão dos principais efeitos gerados por políticas desenvolvimentistas na região, e assim, superar um dos maiores empecilhos para o desenvolvimento agrícola na Amazônia: a escassez de informações.

Quanto as principais metodologias utilizadas nos artigos, o percentual das pesquisas de natureza quantitativa, qualitativa e quali-quantitativa, foi de $55,2 \%$, $34,5 \%$ e $10,3 \%$, respectivamente. No primeiro grupo, as técnicas econométricas para avaliações de impacto utilizando dados secundários se sobressaíram. Os modelos mais utilizados foram as análises de painel data e propensity-score. Para as pesquisas qualitativas os estudos de caso, aplicação de questionários e realização de entrevistas foram as estratégias mais utilizadas neste campo. Similar a estas investigações, os estudos quali-quantitativos realizaram os mesmos procedimentos com a ressalva para tratamentos estatísticos dos dados através da aplicação de t-test e criação de índices, por exemplo.

Semelhante ao estudo de Resende e Mafra (2016), o perfil de grande parte das pesquisas selecionadas se referiram ao Programa diante de três enfoques principais: i) evolução do Programa: em $44,8 \%$ dos estudos as análises deram foco para a distribuição temporal dos financiamentos e os principais impactos da política sobre a economia, produção e desenvolvimento local; ii) beneficiários do PRONAF: as pesquisas que buscaram compreender os resultados do Programa para os sujeitos a quem se destina essa política trazendo discussões relacionadas as dificuldades e/ou facilidades de acesso ao crédito e nível de satisfação dos beneficiários com o PRONAF, foram ao todo $36,2 \%$; iii) opiniões críticas e reflexões: artigos que analisaram o desempenho do Programa como um todo, demonstrando uma série de questionamentos e contradições em sua atuação, 
representaram, 19,0\%. O Quadro 1 ilustra essa categorização para todas as pesquisas selecionadas.

Quadro 1 - Enfoques dos estudos de impacto do PRONAF no Brasil realizados no período de 2000 a 2019.

\begin{tabular}{|c|c|c|c|}
\hline Enfoques & Definição & $\%$ & Autores \\
\hline $\begin{array}{l}\text { Evolução do } \\
\text { Programa }\end{array}$ & $\begin{array}{lrr}\text { Estudos } & r \text { que } \\
\text { investigam } & \text { temas } \\
\text { voltados } & \text { para } & \text { a } \\
\text { evolução } & & \text { dos } \\
\text { financiamentos; } & \\
\text { concentração } & \text { e } \\
\text { aplicação } & \text { dos } \\
\text { recursos; } & \text { impactos } \\
\text { setoriais } & \text { produtivos. } & \\
\text { prodis. }\end{array}$ & $44,8 \%$ & $\begin{array}{l}\text { Ferreira (2006); Magalhães et al. (2006); } \\
\text { Mattei (2007); Medeiros, Guimarães e Holanda } \\
\text { Junior (2009); Silva e Alves Filho (2009); } \\
\text { Damasceno; Khan; Lima (2011); Azevedo e } \\
\text { Pessôa (2011); Souza, Ney e Ponciano } \\
\text { (2011); Souza et al.(2013); Batista e Neder } \\
\text { (2014); Pereira e Nascimento (2014); Sartor et } \\
\text { al. (2014); Mattei (2014); Souza e Barbé } \\
\text { (2014); Pires (2014); Maia, Eusébio e Azevedo } \\
\text { (2014); Souza, Ney e Ponciano (2015); } \\
\text { Antunes et al.(2013); Malheiros et al., (2015); } \\
\text { Marioni et al. (2016); Oliveira, Araújo e Queiroz } \\
\text { (2017); Rodrigues (2019); Corcioli (2019); } \\
\text { Oliveira e Bueno (2019); Conterato e Bráz } \\
\text { (2019); Avelar e Stamm (2019). }\end{array}$ \\
\hline $\begin{array}{l}\text { Beneficiários } \\
\text { do PRONAF }\end{array}$ & $\begin{array}{l}\text { Análises sob a ótica } \\
\text { dos sujeitos a quem } \\
\text { se destina a política. } \\
\text { Reúne pesquisas } \\
\text { sobre a experiência } \\
\text { dos agricultores com } \\
\text { o Programa e seus } \\
\text { efeitos sobre as } \\
\text { relações sociais e de } \\
\text { trabalho. }\end{array}$ & $36,2 \%$ & $\begin{array}{l}\text { Garcia, Castro e Teixeira (2008); Silva et al. } \\
\text { (2013); Capelesso e Cazella (2013); Alves et } \\
\text { al.(2014); Moreira, Silveira e Motter (2014); } \\
\text { Amorim, Eliziário e Terra (2014); Miranda e } \\
\text { Gomes (2016); Spanevello, Matte e Boscardin } \\
\text { (2016); Souza e Hespanhol (2016); Godoi, } \\
\text { Búrigo e Cazella (2016); Guedes e Carvalho } \\
\text { (2016); Guedes e Carvalho (2017); Beltrame e } \\
\text { Pereira (2017); Abreu (2017); Tagore, Canto e } \\
\text { Sobrinho (2018); Borges, Silva e Coutinho } \\
\text { (2018); Fossá, Cormelatto e Mattei (2018); } \\
\text { Carmo e Clemente (2018); Ely et al. (2019); } \\
\text { Magella e Silva (2019); Trentin (2019). }\end{array}$ \\
\hline $\begin{array}{l}\text { Opiniões } \\
\text { críticas e } \\
\text { reflexões }\end{array}$ & $\begin{array}{l}\text { Apontamentos } \\
\text { críticos que ao } \\
\text { demonstrarem } \\
\text { contradições ainda } \\
\text { presentes, } \\
\text { questionam } \\
\text { legitimidade a } \\
\text { Programa. }\end{array}$ & $19,0 \%$ & $\begin{array}{l}\text { Anjos et al. (2004); Guanziroli (2007); Corrêa e } \\
\text { Silva (2007); Wesz Júnior (2010); Magalhães } \\
\text { (2010); Costa e Andrade (2010); Saron e } \\
\text { Hespanhol (2012); Gazolla e Schneider } \\
\text { (2013); Grisa, Wesz Junior e Buchweitz } \\
\text { (2014); Resende e Mafra (2016); Dias e Aguiar } \\
\text { (2016); }\end{array}$ \\
\hline
\end{tabular}

Fonte: dados da pesquisa.

Tendo em conta que o PRONAF é uma política com foco de atuação nas dimensões, sociais, econômicas e produtivas, a seguir serão discutidas seis linhas temáticas mais exploradas por cada artigo. A saber:

i) Concentração dos recursos: apesar do PRONAF estar presente em 98\% dos municípios brasileiros, muitas críticas são feitas sobre seu modelo de distribuição dos financiamentos. Basicamente, a postura dos bancos exibe uma performance vista como uma reedição do período vivenciado na modernização agrícola, em que a parcela de agricultores com melhores condições econômicas 
desfruta de maiores regalias no sistema financeiro, deixando à margem os produtores menos inseridos e as regiões as quais pertencem.

Sobre essa perspectiva, muitas pesquisas (SOUZA; NEY; PONCIANO, 2015; SOUZA et al., 2013; GRISA; WESZ JUNIOR; BUCHWEITZ, 2014; RESENDE; MAFRA, 2016; AZEVEDO; PESSÔA, 2011; entre outros) buscaram entender a fundo essa dinâmica de distribuição, dando ênfase para demonstrar a maneira como o atual modelo de concessão de crédito não reflete a real importância da agricultura familiar em regiões mais fragilizadas como o Norte e Nordeste, haja vista que boa parte dos recursos se concentram na Região Sul do País.

Se tratando da aplicação dos recursos, determinados estudos sinalizaram para um maior direcionamento em atividades características da agricultura patronal, como a produção de commodities (GRISA; WESZ JUNIOR; BUCHWEITZ, 2014; CONTERATO; BRÁZ, 2019; SARON; HESPANHOL, 2012; BORGES; SILVA; COUTINHO, 2018; TRENTIN, 2019). Este resultado é algo que precisa ser visto com muita cautela, pois se sabe que uma das características fundamentais da agricultura familiar é a diversificação produtiva. Por este motivo, coube a alguns autores (GAZOLLA; SCHNEIDER, 2013; GRISA; WESZ JUNIOR; BUCHWEITZ, 2014; RESENDE; MAFRA, 2016; CONTERATO; BRÁZ, 2019) questionarem se o PRONAF de fato vem fortalecendo a agricultura familiar ou apenas continua fazendo "mais do mesmo".

ii) Desenvolvimento local e regional: embora seja uma política essencialmente agrícola, muitos estudos (SILVA; ALVES FILHO, 2009; MARIONI et al. 2016; RODRIGUES, 2019; MAGALHÃES et al. 2005; ANTUNES et al., 2015; SARTOR et al, 2014; e AVELAR; STAMM, 2019) mostraram que o PRONAF é capaz de gerar efeitos econômicos intersetoriais por conta do fornecimento de insumos e transferência de renda para os setores da indústria e serviços. Este processo ocasiona impactos sobre muitas variáveis socioeconômicas locais, como geração de emprego, renda, pessoal ocupado, arrecadação de impostos entre outras.

Outro ponto interessante ressaltado por alguns autores (SARTOR et al., 2014; AVELAR; STAMM, 2019; SILVA; ALVES FILHO, 2009) é que apesar dos efeitos positivos do Programa na economia local, por vezes os impactos exerceram maior influência sobre o setor industrial e de serviços comparativamente ao setor agropecuário. Tal resultado se opõe ao que naturalmente se espera de uma política agrícola, e por isso, Sartor et al. (2014) reforçam sobre os indícios de que o 
PRONAF tem se comportado muito mais como uma política de distribuição de renda do que propriamente de fortalecimento da agricultura familiar.

\section{iii) Assistência técnica e burocratização do acesso ao financiamento:} organizações socias e suporte técnico eficientes estabelecem conexões entre o sistema financeiro e beneficiário. Assim, a ausência de relações de confiança entre os produtores, onerosidade nas operações bancárias, falta de capacitação técnica para elaboração de projetos não convencionais e a carência de suporte técnico em todas as etapas de produção tornam precárias as condições de acesso aos recursos junto aos bancos. Por esta razão, muitos autores (GUEDES; CARVALHO, 2017; MAGELLA; SILVA, 2019; SOUZA; HESPANHOL, 2016; GODOI; BÚRIGO; CAZELLA, 2016; BELTRAME; PEREIRA, 2017; entre outros) fizeram ressalvas sobre a necessidade de melhorar qualitativamente todos estes aspectos para que seja possível alcançar dimensões mais amplas do desenvolvimento.

Associada a estas dificuldades de acesso aos recursos, tem-se o grau de inadimplência do Programa, dado que essa condição não permite o agricultor requerer o crédito junto aos bancos. Embora a não quitação das dívidas tenha sido um traço muito característico do PRONAF, os estudos selecionados neste levantamento não discutiram a fundo essa questão. Entretanto, Amorim, Eliziário e Terra (2014) e Borges, Silva e Coutinho (2019) relataram que alguns dos motivos propulsores para a inadimplência, são: perdas na safra; baixa margem de lucro; e falta de gestão financeira. Outro problema relacionado a isto, e que foi bastante ressaltado pelas pesquisas, diz respeito a demora na liberação dos recursos, conforme apontado por Guedes e Carvalho (2017) e Miranda e Gomes (2016), o que acaba por criar embaraços na execução financeira e técnica do projeto/atividade.

iv) $O$ papel social e as relações de trabalho: diante das várias linhas de atuação do PRONAF, foi possível notar que alguns trabalhos vêm sendo desenvolvidos para compreender os efeitos do Programa sobre as relações sociais entre os diferentes atores desta política. A pesquisa de Spanevello, Matte e Boscardin (2016) analisa o acesso ao crédito mediante as perspectivas das mulheres participantes do PRONAF-Mulher. Com base nos resultados, a criação desta linha específica não foi suficiente para ocasionar maiores mudanças nas relações de trabalho entre homens e mulheres, isto porque o maior poder de decisão ainda se mantém a cargo dos homens. Além disso, as beneficiárias muitas vezes tomam o crédito sob pressão dos maridos/companheiros, que ao esgotarem seus 
limites de financiamento, recorrem as suas parceiras para complementar algum recurso faltoso da atividade.

Outra relação social e de trabalho com aspectos muito interessantes diz respeito ao grupo de pescadores artesanais, detalhado por Capelesso e Cazella (2013) em seu estudo sobre o PRONAF-Pesca no Litoral Sul Catarinense, cujos resultados revelaram baixa adesão desta linha. Entre as principais razões que levaram a isso, estão: prevalência de um sistema informal de financiamento baseado em laços de poder entre pescadores e atravessadores; desconsideração dos bancos sobre a condição financeira momentânea do pescador; exigência de contratos coletivos; e a pouca experiência de relacionamento desses indivíduos com os bancos.

v) Mudanças na unidade produtiva: o acesso aos recursos financeiros viabiliza a manutenção e modernização da propriedade e dos setores agrícola e pecuário por meio da aquisição de insumos, maquinários e construção de benfeitorias. Tais investimentos impactam diretamente sobre a expansão da produtividade e incremento da renda familiar, fazendo com que os produtores encontrem motivações para permanecer no campo. As pesquisas de Ferreira (2006); Pereira e Nascimento (2014); Miranda e Gomes (2016); Souza e Hespanhol (2016); Oliveira e Bueno (2019) e Medeiros, Guimarães e Holanda Júnior (2009) tratam sobre estas questões.

Pereira e Nascimento (2014), ao analisarem a capacidade do PRONAF em contribuir para a redução do hiato entre o potencial produtivo e o produto efetivo da agropecuária no estado do Tocantins, obtiveram resultados satisfatórios, indicando que a política reúne as condições necessárias para reduzir esse hiato na agricultura familiar. Contudo, a pesquisa ressalta que o fornecimento de crédito tem importância complementar, pois compreende ao trabalho familiar 0 fator decisivo no desempenho da produção.

Deste modo, o fortalecimento da capacidade produtiva defendida pelo PRONAF é algo que vem sendo efetivamente incorporado em sua operacionalização, embora o direcionamento dos recursos tenha sido em grande parte para beneficiar agricultores que, conforme mencionado anteriormente, seguem um modelo convencional de produção. Tendo isso em vista, Dias (2016) reforça a necessidade fortalecer os estímulos a geração de renda proveniente de atividades não agrícolas, como o lazer, recreação, turismo rural, entre outras atividades, além de consolidar os canais de comercialização destes serviços. 
vi) Dimensão ambiental: embora um dos objetivos do PRONAF seja o desenvolvimento rural sustentável, poucos estudos (DAMASCENO; KHAN; LIMA, 2011; TAGORE; CANTO; SOBRINHO, 2018; GODOI; BÚRIGO; CAZELLA, 2016 e MAGALHÃES, 2010) deram enfoque aos efeitos do Programa sobre a perspectiva ambiental. Essa temática, de forma geral, foi abordada apenas como um exemplo da criação de linhas para inciativas de produção sustentável. Entretanto, mesmo com tal dificuldade, foram encontrados bons registros sobre a maneira como vem sendo incorporada a preocupação com os recursos ambientais nos financiamentos do PRONAF.

A pesquisa de Magalhães (2010) é um exemplo disto. O autor ao analisar as linhas Florestal e Agroecológica verificou que ambas possuem um baixo desempenho devido à falta de adesão; poucos coeficientes técnicos e financeiros reconhecidos; a difícil comprovação da viabilidade financeira dos Sistemas Agroflorestais (SAFs); falta de mercados consolidados para a comercialização destes produtos; e, por fim, o caráter secundário dado pelo governo nas ações envolvendo a agricultura sustentável.

\section{Considerações Finais}

Esta revisão sistemática permitiu catalogar 58 estudos sobre a temática em questão. As principais localidades em que foram desenvolvidas as investigações referem-se às Regiões Sul e Sudeste; e, entre as abordagens mais utilizadas prevaleceram os estudos de caráter quantitativo. A leitura integral dos estudos selecionados sinalizou para a existência de uma série de desafios que ainda precisam ser superados, como a centralização dos recursos; processos burocráticos e participação pouco efetiva de grupos marginalizados (mulheres, pescadores e outros); comoditização da produção rural; falhas na operacionalização da assistência técnica e a baixa incorporação da sustentabilidade nos esquemas de financiamento. Como sugestão de trabalhos futuros, destaca-se a importância de realizar novas avaliações de impacto focadas nas incoerências citadas anteriormente, visando a produção de conhecimentos que auxiliem no entendimento dessa política, especialmente em localidades pouco estudadas como a Região Norte, para que, a partir destas experiências, possam ser traçados novos caminhos rumo a efetividade do Programa. 


\section{REFERÊNCIAS}

ABREU, T. L. O Programa Nacional de Fortalecimento da Agricultura Familiar no estado da Paraíba: avanços e desafios. Revista Principia - Divulgação Científica e Tecnológica do IFPB, n. 35, p. 125-138, 2017.

ALVES, S. V.; MARTINS, D. D. S.; OLIVEIRA, J. S.; NÓBREGA, A. L. As políticas de convivência com a seca: uma análise da implementação do PRONAF no município de Catolé do Rocha-PB. Revista Verde de Agroecologia e Desenvolvimento Sustentável, v. 9, n. 5, 2014.

AMORIM, F. R. DE; ELIZIÁRIO, R. DE O.; TERRA, L. A. A. O grau de inadimplência do PRONAF no assentamento de reforma agrária de Ibitiúva no município de Pitangueiras-SP. Revista Brasileira de Agropecuária Sustentável, v. 4, n. 1, p. 53-62, 2014.

ANJOS, F. S. DOS.; GODOY, W. I.; CALDAS, N. V.; GOMES, M. C. Agricultura familiar e políticas públicas: impacto do PRONAF no Rio Grande do Sul. Revista de Economia e Sociologia Rural, v. 42, n. 3, p. 529-548, 2004.

ANTUNES, R. L.; CAMARA, M. R. G.; NASCIMENTO, S. P.; SEREIA, V. J.; ANHESINI, J. A. $R$. Programa nacional de crédito da agricultura familiar e impactos nas economias locais no estado do Paraná. Economia \& Região, v. 1, n. 1, p. 69-90, 2013.

ARAUJO, J. A.; VIEIRA FILHO, J. E. R. Análise dos impactos do PRONAF na agricultura do Brasil no período de 2007 a 2016. Rio de Janeiro: (IPEA), 2018.

ARAÚJO, J. G.; SANTOS, M. A. S.; REBELLO, F. K.; OLIVEIRA, C. M.; COSTA, A. D. Crédito rural para aquicultura: uma análise do Fundo Constitucional de Financiamento do Norte no estado do Pará. Revista Eletrônica em Gestão, Educação e Tecnologia Ambiental, v. 19, n. 3, set-dez. 2015, p. 553-562.

AVELAR, F. M.; STAMM, C. Agricultura familiar: efeitos do PRONAF na região Oeste do Paraná. Geosul, v. 34, n. 72, p. 359-394, 2019.

AZEVEDO, F. F.; PESSÔA, V. L. S. O Programa nacional de fortalecimento da agricultura familiar no Brasil: uma análise sobre a distribuição regional e setorial dos recursos. Sociedade \& Natureza, v. 23, n. 3, p. 483-496, 2011.

BANCO CENTRAL DO BRASIL (BCB). Matriz de Dados do Crédito Rural. Disponível em: https://www.bcb.gov.br/. Acesso em: 30 ago. 2020.

BANCO DO NORDESTE DO BRASIL (BNB). Grupos e linhas de crédito PRONAF Quadro resumo (Plano Safra 2019/2020). Disponível em: https://www.bnb.gov.br/documents/165130/228956/PRONAF_PLANO_SAFRA_2019-

2020_TABELA_GRUPOS.pdf/23c356e6-7545-ce72-5cfa-2e4̄bd5a3a58c. Acesso em: 20 ago. 2020 .

BARROS, J. R. M. Política e Desenvolvimento Agrícola no Brasil. In: VEIGA, A. (Ed.). Ensaios sobre política agrícola brasileira. 1. ed. São Paulo: Secretaria da Agricultura, 1979. p. 294.

BATISTA, H. R.; NEDER, H. D. Efeitos do PRONAF sobre a pobreza rural no Brasil (20012009). Revista de Economia e Sociologia Rural, v. 52, n. 1, p. 147-166, 2014.

BELTRAME, G.; PEREIRA, B. A. D. Impactos socioeconômicos ocasionados pelo PRONAF para o Desenvolvimento da Agricultura Familiar. Desenvolvimento em Questão, v. 15, n. 38, p. 87-107, 2017.

BIANCHINI, V. Vinte Anos do PRONAF, 1995-2015: avanços e Desafios. Brasília: SAF/ MDA, 2015. 
BORGES, G. G.; SILVA, M. DO C. L. DA; COUTINHO, E. M. DE C. Análise da importância do PRONAF para os agricultores familiares. Revista Expressão Católica, v. 7, n. 1, p. 20 26, 2018.

BRASIL. Ministério do Desenvolvimento Agrário: 12 anos de transformações, lutas e conquistas. Brasília: Editora Ideal, 2015.

CAPELESSO, A. J.; CAZELLA, A. A. Os Sistemas de Financiamento na Pesca Artesanal: um estudo de caso no. Revista de Economia e Sociologia Rural, v. 51, n. 2, p. 275-294, 2013.

CARMO, J. G. DO; CLEMENTE, E. C. A contribuição do PRONAF para o desenvolvimento rural: uma análise dos seus efeitos e desdobramentos para os assentados rurais nos municípios de Teodoro Sampaio e Caiuá-SP. Revista Tamoios, v. 14, n. 1, p. 31-50, 2018.

CASTRO, P. R. V. Do Estado ao Mercado: a trajetória do crédito rural brasileiro e as diversas fontes de financiamento, período colonial ao século XXI. Informações Econômicas, v. 47, n. 3, p. 40-49, 2017.

CONSELHO NACIONAL DE DESENVOLVIMENTO CIENTÍFICO E TECNOLÓGICO (CNPQ). Censo 2016 - Distribuição dos pesquisadores segundo a região geográfica. Disponível em: http://lattes.cnpq.br/web/dgp/por-regiao1. Acesso em: 30 ago. 2020.

CONTERATO, M. A.; BRÁZ, C. A. O processo de especialização produtiva dos agricultores familiares da Zona Sul do Rio Grande do Sul através do PRONAF-custeio. Redes, v. 24, n. 3, p. 12-34, 2019.

CORCIOLI, G. Evolução do PRONAF no Estado de Goiás: tendência de concentração de investimentos em atividades pecuárias tradicionais. Boletim Goiano de Geografia, v. 39, p. 1-21, 2019.

CORRÊA, V. P.; SILVA, F. F. Análise das Liberações Recentes de Recursos do PRONAF: Uma Mudança na Lógica de Distribuição? Revista Econômica do Nordeste, v. 38, n. 1, p. 48-66, 2007.

COSTA, F. A.; ANDRADE, W. D. C. Instituições e dinâmica dependente de trajetória na Amazônia: as políticas para arranjos produtivos locais no Pará. Amazônia: Ciência e Desenvolvimento, v. 6, n. 1, p. 145-177, 2010.

CRONIN, P.; RYAN, F.; COUGHLAN, M. Undertaking a literature review: a step-by-step approach. British Journal of Nursing, v. 17, n. 1, p. 38-43, 2008.

DAMASCENO, N. P.; KHAN, A. S.; LIMA, P. V. P. S. O impacto do PRONAF sobre a sustentabilidade da agricultura familiar, geração de emprego e renda no Estado do Ceará. Revista de Economia e Sociologia Rural, v. 49, n. 1, p. 129-156, 2011.

DE SOUZA, P. M.; NEY, M. G.; PONCIANO, N. J. Evolução da distribuição dos financiamentos do PRONAF entre as unidades da federação, no período de 1999 a 2009. Revista Brasileira de Economia, v. 65, n. 3, p. 303-313, 2011.

DIAS, G. M. DE O.; AGUIAR, L. M. B. DE. PRONAF: Agricultura Familiar Camponesa, Desenvolvimento Territorial Rural e Multifuncionalidade em São João Del-Rei/MG. Revista Geográfica Acadêmica, v. 10, n. 2, p. 138-153, 2016.

ELY, R. A.; PARFITT, R.; CARRARO, A.; RIBEIRO, F. G. Rural credit and the time allocation of agricultural households: The case of PRONAF in Brazil. Review of Development Economics, v. 23, n. 4, p. 1863-1890, 2019.

FERREIRA, G. A. L. As políticas setoriais para a agricultura familiar: uma avaliação do PRONAF. RA'E GA - O Espaco Geográfico em Análise, n. 11, p. 77-88, 2006. 
FOSSÁ, J. L.; COMERLATTO, D.; MATTEI, L. F. O Programa Nacional de Fortalecimento da Agricultura Familiar (PRONAF) na percepção de agricultores familiares. Revista Brasileira de Planejamento e Desenvolvimento, v. 7, n. 5, p. 670-693, 2018.

GARCIA, M. D. O.; CASTRO, E. R. DE; TEIXEIRA, E. C. Eficácia do PRONAF-crédito no município de São Miguel do Anta/MG. Revista Brasileira de Gestão e Desenvolvimento Regional, v. 4, n. 2, p. 154-173, 2008.

GAZOLLA, M.; SCHNEIDER, S. Qual "fortalecimento" da agricultura familiar? Uma análise do PRONAF crédito de custeio e investimento no rio grande do sul. Revista de Economia e Sociologia Rural, v. 51, n. 1, p. 45-68, 2013.

GODOI, T. G.; BÚRIGO, F. L.; CAZELLA, A. A. A sustentabilidade dos financiamentos do PRONAF para a agricultura familiar. Desenvolvimento e Meio Ambiente, v. 38, p. 637661, 2016.

GRISA, C.; SCHNEIDER, S. Três gerações de políticas públicas para a agricultura familiar e formas de interação entre sociedade e estado no Brasil. Revista de Economia e Sociologia Rural, v. 52, p. 125-146, 2014.

GRISA, C.; WESZ JUNIOR, V. J.; BUCHWEITZ, V. D. Revisitando o PRONAF: Velhos questionamentos, novas interpretações. Revista de Economia e Sociologia Rural, v. 52, n. 2, p. 323-346, 2014.

GRZYBOWSKI, C.; MOTTA, E.; PINTO, J. R. L.; MATTEI, L.; MÉLLO, L.; CERQUEIRA, L.; TIBAU, M.; DELGADO, N. G.; SOARES, S. Relatório PRONAF: Resultados da Etapa Paraná. Rio de Janeiro: 2006.

GUANZIROLI, C. E. PRONAF dez anos depois: Resultados e perspectivas para o desenvolvimento rural. Revista de Economia e Sociologia Rural, v. 45, n. 2, p. 301-328, 2007.

GUEDES, A. A. A.; CARVALHO, D. M. DE. Percepção dos agricultores familiares de Garanhuns-PE quanto a possíveis dificuldades de acesso ao PRONAF-B. Revista Econômica do Nordeste, v. 47, n. 3, p. 15-30, 2016.

GUEDES, A. A. A.; DE CARVALHO, D. M. Dificuldades e gargalos de acesso ao PRONAF B em Garanhuns - PE. Revista Brasileira de Gestão e Desenvolvimento Regional, v. 13, n. 3, p. 200-222, 2017.

INSTITUTO BRASILEIRO DE GEOGRAFIA E ESTATÍSTICA (IBGE). Censo Agropecuário 2017. Disponível em: https://sidra.ibge.gov.br/pesquisa/censo-agropecuario/censoagropecuario-2017. Acesso em: 15 ago. 2020.

INSTITUTO DE PESQUISAS ECONÔMICAS APLICADAS (IPEA). Índice geral de preços disponibilidade interna (IGP-DI) - Geral. Disponível em: http://www.ipeadata.gov.br/Default.aspx. Acesso em: 15 ago. 2020.

MAGALHÃES, A. M.; SILVEIRA NETO, R.; DIAS, F. M.; BARROS, A. R. A experiência recente do PRONAF em Pernambuco: uma análise por meio de propensity score. Economia Aplicada, v. 10, n. 1, p. 57-74, 2006.

MAGALHÃES, R. M. A política de apoio à agricultura familiar na conservação da biodiversidade no Brasil. Desenvolvimento e Meio Ambiente, n. 21, p. 89-101, 2010.

MAGELLA, M. S.; SILVA, W. E. DA. A utilização dos recursos do Programa Nacional Para o Fortalecimento da Agricultura Familiar no município de Mogi das Cruzes. Revista Eniac Pesquisa, v. 8, n. 2, p. 238-253, 2019.

MAIA, A. G.; EUSÉBIO, G. DOS S.; AZEVEDO, A. A. O acesso aos recursos do PRONAF e diferenciais socioeconômicos de assentados na Amazônia Legal. Amazônia: Ciência e Desenvolvimento, v. 9, n. 18, p. 7-23, 2014. 
MALHEIROS, M. A. D. C.; HÖFLER, C. E.; PIVOTTO, B. R.; WARMBIER, B. G. A influência do PRONAF na economia regional e na geração de renda em pequenas propriedades rurais. Revista GESTO, v. 3, n. 2, p. 1-13, 2015.

MARIONI, L. DA S.; VALE, V. A.; PEROBELLI, F. S.; FREGUGLIA, R. S. Uma aplicação de regressão quantílica para dados em painel do PIB e do PRONAF. Revista de Economia e Sociologia Rural, v. 54, n. 2, p. 221-242, 2016.

MATTEI, L. Evolução do crédito do PRONAF para as categorias de agricultores familiares A e A/C entre 2000 e 2010. Revista Econômica do Nordeste, v. 45, n. 2014, p. 58-69, 2014.

MATTEI, L. Impactos do PRONAF: análise de indicadores. Brasília: NEAD Estudos, 2005.

MATTEI, L. Políticas de Apoio ao Desenvolvimento da Agricultura Familiar no Brasil: o caso recente do PRONAF. Revista Econômica do Nordeste, v. 38, n. 1, p. 143-158, 2007.

MATTEI, L. PRONAF 10 anos: Mapa da Produção Acadêmica. Brasília: NEAD Estudos, 2006.

MEDEIROS, H. R. DE; GUIMARÃES, V. P.; HOLANDA JÚNIOR, E. V. The use of linear programming to evaluate the impact of credit for investiments in small goat farms. Tropical and Subtropical Agroecosystems, v. 11, p. 7-11, 2009.

MIRANDA, D. L. R.; GOMES, B. M. A. Programa nacional de fortalecimento da agricultura familiar: trajetórias e desafios no Vale do Ribeira, Brasil. Sociedade \& Natureza, v. 28, n. 3, p. 397-408, 2016.

MOREIRA, V. DE S.; SILVEIRA, S. DE F. R.; MOTTER, K. Z. Avaliação de impacto do PRONAF B sobre a satisfação de agricultores familiares em municípios de Minas Gerais. Estudos Sociedade e Agricultura, v. 22, n. 2, p. 1-17, 2014.

OLIVEIRA, G. R.; ARAÚJO, F. M. DE; QUEIROZ, C. C. DE. A importância da assistência técnica e extensão rural (Ater) e do crédito rural para a agricultura familiar em Goiás. Boletim Goiano de Geografia, v. 37, n. 3, p. 528-551, 2017.

OLIVEIRA, R. A. DE; BUENO, L. R. O impacto do financiamento do PRONAF sobre indicadores agrícolas nas lavouras do Estado do Paraná: uma análise de dados em painel. Redes, v. 24, n. 1, p. 292-309, 2019.

PEREIRA, E. L.; NASCIMENTO, J. S. Efeitos do PRONAF sobre a produção agrícola familiar dos municípios tocantinenses. Revista de Economia e Sociologia Rural, v. 52, n. 1, p. 139-156, 2014.

PIRES, M. J. DE S. Um estudo da estrutura e evolução do Programa Nacional de Fortalecimento da Agricultura Familiar (PRONAF): 2000 a 2010. Revista Econômica do Nordeste, v. 45, p. 97-110, 2014.

RAMOS, S. Y.; MARTHA JUNIOR, G. B. Evolução da Política de Crédito Rural Brasileira. Documentos, 292. Planaltina-DF: Embrapa Cerrados, 2010.

RESENDE, C. M.; MAFRA, R. L. M. Desenvolvimento rural e reconhecimento: Tensões e dilemas envolvendo o PRONAF. Revista de Economia e Sociologia Rural, v. 54, n. 2, p. 261-280, 2016.

REVISTA DE ECONOMIA E SOCIOLOGIA RURAL. Disponível em: https://www.revistasober.org/. Acesso em: 15 ago. 2020.

RODRIGUES, G. M. O PRONAF na Zona da Mata Mineira: Efeitos nos PIBs total e setorial dos municípios. Revista de Economia e Sociologia Rural, v. 57, n. 1, p. 30-47, 2019.

SARON, F. DE A.; HESPANHOL, A. N. O PRONAF e as políticas de desenvolvimento rural no Brasil: o desafio da (re)construção das políticas de apoio à agricultura familiar. Geo UERJ, v. 2, n. 23, p. 656-683, 2012. 
SARTOR, M. J.; CAMARA, M. R. G.; NASCIMENTO, S. P.; SATO, S. T. Contribuição do PRONAF para o crescimento das economias locais: Uma análise para o Brasil e Regiões. Economia \& Região, v. 2, n. 1, p. 7-27, 2014.

SCHNEIDER, S.; MATTEI, L.; CAZELLA, A. A. Histórico, caracterização e dinâmica recente do PRONAF - Programa Nacional de Fortalecimento da Agricultura Familiar. In: SCHNEIDER, S.; SILVA, M. K.; MARQUES, P. E. M. (Eds.). Políticas Públicas e Participação Social no Brasil Rural. Porto Alegre: 2004. p. 21-50.

SILVA, E. L. DA; MENEZES, E. M. Metodologia da Pesquisa e Elaboração de Dissertação. 3. ed. Florianópolis: Laboratório de Ensino a Distância da UFSC, 2001.

SILVA, K. M. D.; SANTIAGO, W. P.; ARAUJO, C. A. L.; FEITOSA, M. N.; SILVA, R. S.; ARAUJO, M. P. S. N. Desenvolvimento na concepção seniana: utopia ou realidade no sertão mineiro? Espacios, v. 34, n. 8, p. 15, 2013.

SILVA, S. P. Políticas públicas, agricultura familiar e desenvolvimento territorial: uma análise dos impactos socioeconômicos do PRONAF no Território Médio Jequitinhonha - MG. Texto para discussão no 1693. Brasília: (IPEA), 2012.

SILVA, S. P.; ALVES FILHO, E. Impactos Econômicos do PRONAF em Territórios Rurais: Um Estudo para o Médio Jequitinhonha - MG. Revista Econômica do Nordeste, v. 40, n. 3, p. 481-498, 2009.

SOUZA, P. C.; HESPANHOL, A. N. O papel exercido pelo PRONAF em municípios de pequeno porte no Oeste Paulista. Geo UERJ, n. 28, p. 381-409, 2016.

SOUZA, P. M. DE; BARBÉ, L. DA C. Desigualdades regionais na distribuição dos financiamentos do PRONAF: uma análise do período de 1998 a 2012. Revista Econômica do Nordeste, v. 45, p. 37-50, 2014.

SOUZA, P. M. DE; NEY, M. G.; PONCIANO, N. J. Análise da distribuição dos financiamentos rurais entre os estabelecimentos agropecuários brasileiros. Revista de Economia e Sociologia Rural, v. 53, n. 2, p. 251-270, 2015.

SOUZA, P. M. DE; PONCIANO, N. J.; NEY, M. G.; FORNAZIER, A. Análise da evolução do valor dos financiamentos do PRONAF-Crédito (1999 a 2010): Número, valor médio e localização geográfica dos contratos. Revista de Economia e Sociologia Rural, v. 51, n. 2, p. 237-254, 2013.

SPANEVELLO, R. M.; MATTE, A.; BOSCARDIN, M. Crédito rural na perspectiva das mulheres trabalhadoras rurais da agricultura familiar: uma análise do Programa Nacional de Fortalecimento da Agricultura Familiar (PRONAF). Polis (Santiago), v. 44, p. 1-18, 2016.

SPOLADOR, H. F. S. Reflexões sobre a experiência brasileira de financiamento da agricultura. 2001. Dissertação (Mestrado em Ciências) - Instituto de Economia Aplicada, Escola Superior de Agricultura "Luiz de Queiroz", Piracicaba-SP.

TAGORE, M. D. P. B.; CANTO, O. DO; SOBRINHO, M. V. Políticas públicas e riscos ambientais em áreas de várzea na Amazônia: o caso do PRONAF para produção do açaí. Desenvolvimento e Meio Ambiente, v. 45, p. 194-214, 2018.

TRENTIN, I. C. L. Programa Nacional de Fortalecimiento de la Agricultura familiar: Promoción de la Agricultura Familiar o Agronegocio en Brasil? Revista Verde de Agroecologia e Desenvolvimento Sustentável, v. 14, n. 4, p. 554-561, 2019.

TURA, Letícia Rangel; COSTA, Francisco de Assis (Org.). Campesinato e Estado na Amazônia: impactos do FNO no Pará. Brasília: Brasília Jurídica, 2000.

WESZ JUNIOR, V. J. Política Pública de Agroindustrialização na Agricultura Familiar: Uma Análise do PRONAF-agroindústria. Revista de Economia e Sociologia Rural, v. 48, n. 4, p. 567-596, 2010. 


\section{NOTAS DE AUTOR}

\section{CONTRIBUIÇÃO DE AUTORIA}

Carina Chagas Madeira de Souza - Concepção da pesquisa; Coleta de dados; Análise de dados; Elaboração do manuscrito; Participação ativa da discussão dos resultados.

Fabrício Khoury Rebello - Concepção da pesquisa; Participação ativa da discussão dos resultados; Revisão; Aprovação da versão final do trabalho.

Marcos Antônio Souza dos Santos - Concepção da pesquisa; Participação ativa da discussão dos resultados; Revisão; Aprovação da versão final do trabalho.

\section{FINANCIAMENTO}

O desenvolvimento desta pesquisa contou com apoio da Coordenação de Aperfeiçoamento de Pessoal de Nível Superior (CAPES) por meio da concessão de bolsa de mestrado para a primeira autora. O Projeto de Pesquisa "Evolução, Concentração Espacial e Impactos da Política de Crédito Rural na Amazônia Brasileira" está registrado na Pró-Reitoria de Pesquisa e Desenvolvimento Tecnológico da Universidade Federal Rural da Amazônia (UFRA), sob o número PVRH168-2012.

\section{CONSENTIMENTO DE USO DE IMAGEM}

Não se aplica.

\section{APROVAÇ̃̃O DE COMITÊ DE ÉTICA EM PESQUISA}

Não se aplica.

\section{CONFLITO DE INTERESSES}

Não há conflito de interesses.

\section{LICENÇA DE USO}

Este artigo está licenciado sob a Licença Creative Commons CC-BY. Com essa licença você pode compartilhar, adaptar, criar para qualquer fim, desde que atribua a autoria da obra.

\section{HISTÓRICO}

Recebido em: 28-09-2020

Aprovado em: 07-09-2021 